\title{
Prevalence of hepatitis E virus infection in wild boars from Spain: a possible seasonal pattern?
}

\author{
Antonio Rivero-Juarez ${ }^{1 *}$ D, María A. Risalde ${ }^{1}$, Mario Frias', Ignacio García-Bocanegra², Pedro Lopez-Lopez', \\ David Cano-Terriza², Angela Camacho1, Saul Jimenez-Ruiz², Jose C. Gomez-Villamandos ${ }^{3}$ and Antonio Rivero ${ }^{1,4}$
}

\begin{abstract}
Background: It has been shown that wildlife can serve as natural reservoirs of hepatitis E virus (HEV). The wild boar (Sus scrofa) is probably the main natural reservoir of HEV and could therefore represent an important route of transmission in Europe, especially in regions where game meat is widely consumed. We evaluated the prevalence of HEV infection in wild boar in the south of Spain, with the aim of identifying associated risk factors. A cross-sectional study that included hunted wild boar was carried out during the 2015/2016 hunting season (October 15 to February 15) in Andalusia (southern Spain). The outcome variable was HEV infection, defined as amplification of HEV RNA in serum by RT-PCR.
\end{abstract}

Results: A total of 142 animals, selected from 12 hunting areas, were included and formed the study population. Thirty-three wild boars (23.2\%; 95\% Cl: 16.8\%-30.7\%) were positive for HEV infection. Prevalence peaked in October and November, then gradually declined until the end of December. After multivariate analysis, only hunting date was independently associated with HEV infection across sex and age.

Conclusions: Our study found a relatively high prevalence of HEV infection in wild boar in the south of Spain, suggesting that prevalence may depend on the season when the animal is hunted. In consequence, the potential risk of zoonotic transmission could fluctuate.

Keywords: Hepatitis E, Wild boar, Prevalence, Seasonality, Foodborne

\section{Background}

Hepatitis E virus (HEV) is an emerging cause of viral hepatitis in developed countries [1,2]. The main route of transmission is the consumption of raw or undercooked pork, and pigs have been identified as the main host of HEV [3]. It has been shown that other animals, wildlife in particular, can act as natural reservoirs of HEV [4]. Among wildlife species, the wild boar (Sus scrofa) is probably the main reservoir of HEV [5] and could therefore represent an important route of transmission in Europe, especially in regions where game meat is widely consumed. In this respect, we recently described a familial

\footnotetext{
*Correspondence: arjvet@gmail.com

${ }^{1}$ Infectious Diseases Unit. Instituto Maimonides de Investigación Biomédica

de Córdoba (IMIBIC), Hospital Universitario Reina Sofía de Córdoba.

Universidad de Córdoba, $2^{\circ}$ Floor. Box 134.Avenida Menendez Pidal s/n

14004 Córdoba, Spain

Full list of author information is available at the end of the article
}

HEV outbreak in our area that was linked to the consumption of wild boar meat, with a secondary finding in our analysis being a high prevalence of HEV in wild boar [6]. It has been proven experimentally that HEV-infected wild boar can transmit the infection to other animals, such as pigs [4, 7]. This plays an important role in countries where extensive pig farming is widespread, because it facilitates contact between domestic pigs and sympatric species and increases the risk of inter-species transmission. For this reason, the evaluation of HEV infection in wild boar and the identification of risk factors affecting transmission is important in order to determine the zoonotic potential of this emerging viral infection and enable control measures to be established.

Risk factors associated with HEV infection have barely been studied in humans. HEV infection has been associated with older males and certain genetic factors [8-10], 
although the reasons remain unknown. At the same time, living in certain regions has also been associated with a higher prevalence of $\operatorname{HEV}[11,12]$. Here we evaluated the prevalence of HEV infection in wild boar in the south of Spain in order to identify associated risk factors.

\section{Methods}

\section{Study design and population}

A cross-sectional study that included hunted wild boar was carried out in Andalusia (southern Spain) $\left(36^{\circ} \mathrm{N}-38^{\circ}\right.$ $\left.600 \mathrm{~N}, 1^{\circ} 750 \mathrm{~W}-7^{\circ} 250 \mathrm{~W}\right)$ during the 2015/2016 hunting season (October 15th to February 15th). Age was determined on the basis of tooth eruption and animals of less than 12 months old were classified as juveniles, those between 12 and 24 months as sub-adults, and those over 2 years old as adults. All animals were classified according to sex. The sample size was calculated on the assumption that $10 \%$ of the samples would be positive for HEV. Hence, assuming a confidence interval of $95 \%$, the minimum sample size was estimated at 139 animals.

\section{Variable collection and definition}

A whole blood sample was obtained from all hunted animals by puncture of the cavernous sinus of the dura mater [13]. Serum was obtained from whole blood. Epidemiological variables were collected and included age, sex, date of sample collection, and hunting area.

The outcome variable was HEV infection, defined as amplification of HEV RNA in serum by reverse transcription polymerase chain reaction (RT-PCR).

\section{RT-PCR for detection of HEV}

Viral RNA was extracted from 200ul of serum using the commercial QIAamp MinElute Virus Spin Kit (QIAgen. Hilden, Germany) and an automated procedure (QIAcube. QIAgen, Hilden, Germany). Samples were frozen at $-80{ }^{\circ} \mathrm{C}$ until analysis. For diagnosis of HEV infection, RT-PCR was performed using the LightCycler 480 system (Roche. Basel, Switzerland) described elsewhere [14]. For the reaction, the QIAgen One step PCR Kit (QIAgen, Hilden, Germany) was used. The primers $(15 \mu \mathrm{Mol})$ employed were: sense primer HEV5260 (5'-GGTGGTTTCTGGGGTGAC-3') and antisense primer HEV5330 (5'-AGGGGTTGGTTGGAT GAA-3'). The probe employed $(20 \mu \mathrm{Mol})$ was HEV5283 (5'-FAM-TGATTCTCAGCCCTTCGC-TAMRA-3'). The thermal profile was $50{ }^{\circ} \mathrm{C}$ for $30 \mathrm{~min}$ and $95{ }^{\circ} \mathrm{C}$ for $15 \mathrm{~min}$, followed by 45 cycles of $94{ }^{\circ} \mathrm{C}$ for $10 \mathrm{~s}, 55^{\circ} \mathrm{C}$ for 20s and $72{ }^{\circ} \mathrm{C}$ for $60 \mathrm{~s}$. An external (in-run) standard curve was applied to calculate HEV viral load using a WHO Standard HEV strain supplied by the PaulEhrlich-Institute (code 6329/10).

\section{Statistical analysis}

HEV prevalence was estimated from the ratio of positive samples to the total number of samples analyzed, with exact binomial confidence intervals of 95\%. Throughout the study, we calculated prevalence by age and sex every week in order to evaluate the possible increase or decrease in HEV prevalence over time. Categorical variables were expressed as numbers of cases (percentage). Frequencies were compared using the $\chi^{2}$ test or Fisher's exact test, and significance was set at a two-tailed $p$-value of less than 0.05 . Bivariate analysis was carried out to discover the variables related to HEV infection, and multivariate logistic regression analysis was also performed. Analyses were carried out using the SPSS statistical software package, version 18.0 (IBM Corporation, Somers, NY, USA), GraphPad Prism, version 6 (Mac OS X version; GraphPad Software; San Diego, California, USA) and Winpepi software, version 11.36 (Brixton Health).

\section{Results \\ Population}

A total of 142 animals were included and constituted the study population. These animals were selected from 12 hunting areas (Fig. 1). Sixty-four animals were male (45.1\%) and 78 females (64.9\%). Ninety-seven were adults (68.4\%) and 45 non-adults (31.6\%).

\section{HEV infection prevalence and associated factors}

Thirty-three wild boars (23.2\%; 95\% CI: 16.8\%-30.7\%) were positive for HEV infection.

When prevalence was compared and analyzed according to sex, 20 males (31.2\%; 95\% CI: $21.2 \%-43.4 \%)$ and 13 females (16.7\%; 95\% CI: 9.9\%-16.9\%) ( $p=0.047)$ presented HEV infection. No significant differences in prevalence were found between adults (25 of 97, 25.8\%; 95\% CI: $18.1 \%-35.3 \%$ ) and non-adults (8 of 45, 17.8\%; 95\% CI: $9 \%-31.6 \%)(p=0.394)$. An analysis of prevalence according to the week when the animals were hunted showed that it was higher in the first weeks of the study than at the end of the hunting season, February 15th (Fig. 2). Prevalence peaked in October and November, then gradually declined until the end of December. The prevalence of HEV infection varied between 60 and $0 \%$, depending on the date of sample collection (Fig. 2).

By multivariate analysis, only hunting date was independently associated with HEV infection across sex and age (Table 1).

\section{Discussion}

Our study found a $23.2 \%$ prevalence of active HEV infection in wild boars in the south of Spain. Interestingly, the prevalence varied significantly according to the period of the hunting season, with a higher HEV prevalence during the last weeks of October and the first 


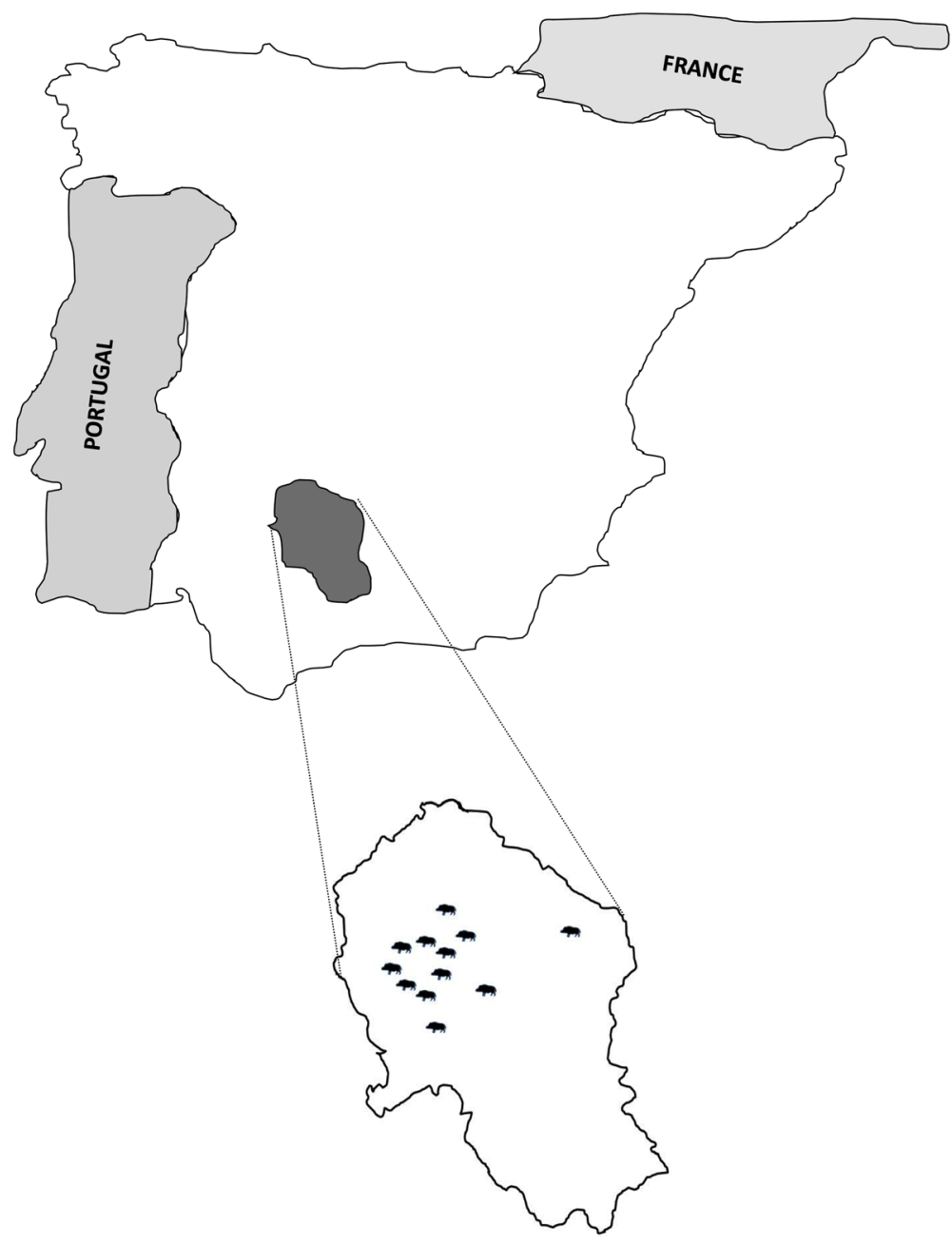

Fig. 1 Hunting area sampling included in the study

weeks of November. This finding suggests a possible seasonal pattern for HEV infection in this species.

Studies performed in Europe have reported a variable prevalence of $\mathrm{HEV}$ infection in wild boar, fluctuating between 2 and 68\%. A study performed in North Germany showed an HEV prevalence of $5.3 \%(10 / 189)$ [15], while in Central Germany it was $15.2 \%$ (7/46) [16] and rose to $68 \%$ in other areas [17]. Elsewhere, countries such as Italy and the Netherlands have reported a prevalence of $9.4 \%(6 / 64)$ and $8 \%(8 / 106)$, respectively [18, $19]$, while in Estonia and Hungary, the reported prevalence was $17.2 \%(81 / 471)$ and $12 \%(9 / 74)$ [20, 21]. Our results are consistent with those previously reported in Central Spain, where 27 out of 138 (19.6\%) animals tested positive for HEV [22]. Our study shows an HEV prevalence of $23.2 \%$. Differences between studies could be associated with various factors, including the sensitivity and specificity of the RT-PCR assay employed. These studies however did not consider external factors to explain the differences. Other studies evaluated risk factors associated with HEV infection in wild boar and identified host and environmental factors. Burri et al. studied 303 serum samples collected from wild boar killed between 2008 and 2012 in 10 different cantons in Switzerland [23]. That study reported a HEV seroprevalence of $12.5 \%$ and found that age (adults $=22.5 \%$ ) and region of origin were factors associated with higher HEV seroprevalence [23]. Likewise, a study carried out in France found that the seroprevalence of HEV IgG antibodies was higher in the south $(22.6 \%)$ than in the central part (9\%) or the north $(7.3 \%)$ [24]. In another study performed in Corsica, Jori et al. found that hunting season and age were risk factors for HEV seroprevalence [25]. Interestingly, hybrid wild boar showed higher HEV seroprevalence than pure wild boar and domestic farm pigs, suggesting they play an important role in the HEV reservoir [25]. Finally, using RT-PCR, Shielke et al. reported a higher prevalence of HEV infection in wild boars hunted in rural habitats than in urban areas [26], indicating that there may be a more efficient virus 


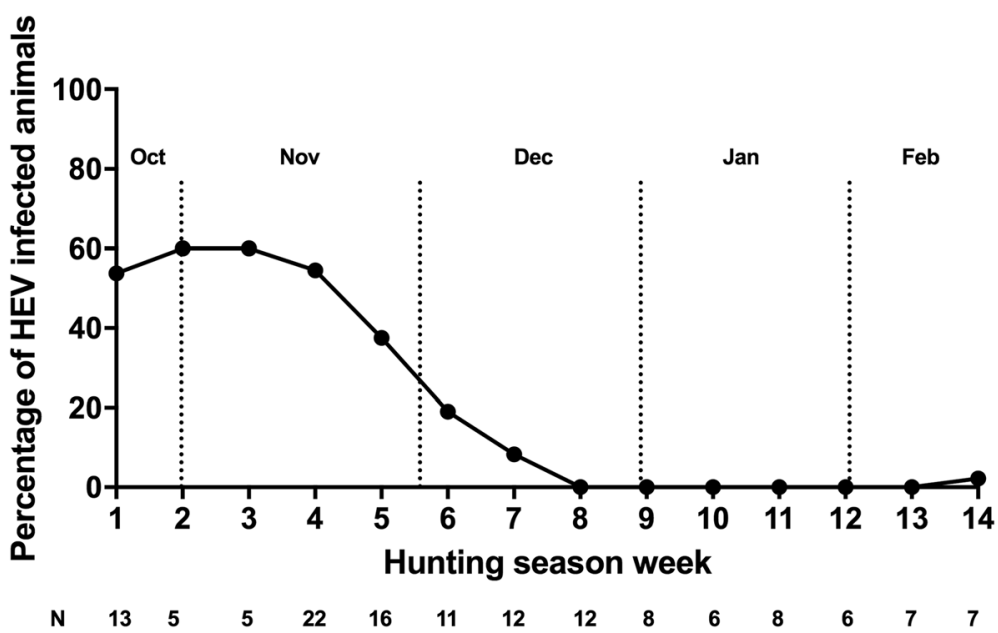

Fig. 2 The prevalence of hepatitis $E$ virus during each week of the hunting season (Oct 15 to Feb 15)

spread in wild boar populations in rural settings. Our study did not find that either age or sex were risk factors for HEV infection, a finding previously reported by others [27]. Our findings did however suggest that other factors, such as the season, could affect the rate of HEV infection in wild boar. In this respect, our study found that the major peak of HEV infection in wild boar was October and November, and then decreased significantly during the rest of the hunting season until February.

Seasonal patterns of HEV infection have previously been described in humans from Asian countries and are clearly linked to environmental factors, such as monsoons and floods, which have a markedly seasonal behavior. In this respect, one study conducted in China showed that the cumulative number of cases of acute HEV is concentrated in the cold season [28]. In studies carried out in India, Pakistan and Nepal, peak HEV infection is linked to floods during the monsoon season [29]. In these countries, the cumulative number of cases can easily be explained as due to the principal route of HEV transmission, which is fecal-oral [8]. Likewise, the authors of a study conducted in China that included farm pigs also described a seasonal pattern, with a major peak of HEV infection being reported in March-April in Eastern China, and a secondary peak in September-October in Southwest China [30]. Nevertheless, in countries where the main route of transmission in humans is via consumption of contaminated food, the seasonal behavior of the disease has not been well established and remains controversial. A study performed in the Southwest of England found that the highest number of cases occurred in the spring and summer [31], although the reason was unknown. By contrast, in another study carried out in France involving cases collected over a 5 -year period, no seasonal variation in the number of cases of HEV infection cases was found at any time [32]. Our study suggests that there is a seasonal component in the prevalence of HEV infection in wild boar, with most cases concentrated in late autumn and gradually decreasing in early winter. This finding is striking and represents the first evidence of an environmental influence on HEV infection in a European country. The explanation for this, bearing in mind current knowledge of the epidemiology and pathogenesis of HEV, is unknown.

Table 1 Multivariate logistic regression model of HEV infection

\begin{tabular}{llllll}
\hline Variable & Condition & $N$ & HEV-infected & OR $(95 \%$ Cl $)$ & $1.84(0.69-4.92)$ \\
\hline Sex & Male & 64 & 20 & 1 & 0.22 \\
Age & Female & 78 & 13 & $1.706(0.55-5.23)$ & 1 \\
Hunting date & Adult & 97 & 25 & $44.73(8.49-235.53)$ & 0.35 \\
& Non-adult & 45 & 8 & $28.09(5.94-132.67)$ & $<0.001$ \\
& Oct 15 - Nov 15 & 23 & 13 & $1.03(0.13-2.89)$ & 0.001
\end{tabular}

Legend: $N$ number of animals, HEV hepatitis E virus, OR odds ratio, 95\% Cl 95\% confidence interval, Oct October, Nov November, Dec December, Jan January, Feb February 
An important point is that the lower prevalence rate in our study coincided with the reproductive season, which is usually between late November and January, when there is extensive contact between animals and the risk of transmission would therefore be expected to be much higher. Our study in fact found the opposite; there was a very low rate of $\mathrm{HEV}$ infection in this period compared with the pre-reproductive season. This could be explained by a route of transmission in wild boar that is as yet unknown, as well as by direct contact between the animals, and this may occur in the first weeks of autumn. It should also be mentioned that at the beginning of this period, extensive Iberian pig farming in the southwest of the Iberian Peninsula occupies agricultural land associated with hunting areas, which leads to increased animal population densities, and spaces and resources being shared with other wild animals. This favors an interspecies transmission of pathogens that needs to be elucidated. These points require further investigation.

Several limitations should be noted in this work. Firstly, our study evaluated only the prevalence of HEV infection in a single hunting season and a single region, and we were therefore unable to establish whether the seasonal behavior observed in our study can be extrapolated to other areas or later hunting seasons. Finally, we did not include other environmental or behavioral factors that may have influenced HEV prevalence in these animals, which may explain the seasonality found in our study.

\section{Conclusions}

Our study found a relatively high prevalence of HEV infection in wild boar in the south of Spain. This finding suggests that the transmission of HEV infection to humans via meat consumption or contact with infected boar found in the wild may be an important factor. Nevertheless, our study suggests that prevalence may depend on the season when the animal was hunted, and the potential risk of zoonotic transmission may therefore fluctuate.

\section{Abbreviations}

95\% Cl: 95\% confidence interval; Dec: December; Feb: February;

HEV: Hepatitis E virus; Jan: January; N: Number of animals; Nov: November; Oct: October; OR: Odds ratio

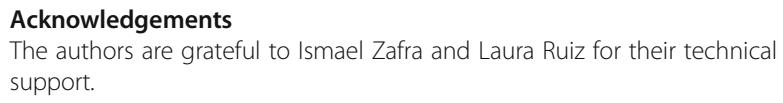

\section{Funding}

This work was supported by the Ministerio de Sanidad (RD12/0017/0012) integrated in the Plan Nacional de I +D +1 and cofinanced by the ISCIII-Subdirección General de Evaluación and the Fondo Europeo de Desarrollo Regional (FEDER), and Fundación para la Investigación en Salud (FIS) del Instituto Carlos III (PI16/01297). The funders did not play any role in the design, conclusions or interpretation of the study.

\section{Availability of data and materials}

All data generated or analyzed during the study are included in this published article. The datasets used and/or analyzed during the present research project are available from the corresponding author on reasonable request.

\section{Authors' contributions}

Dr. Rivero-Juarez had full access to all of the data in the study and takes responsibility for the integrity of the data and the accuracy of the data analysis. Study concept and design: ARJ, MAR, MF, IGB, AR. Analysis and interpretation of the data: ARJ, MF, IGB. Drafting of the manuscript: ARJ, AR. Critical revision of the manuscript for important intellectual content: All authors. Statistical analysis: ARJ. Obtained funding: ARJ. Acquisition of animal samples and data: DCT, SJR, PLL Perform the experiment and technical procedures: ARJ, DCT, SJR, PLL. Study supervision: AR. All authors read and approved the final manuscript.

\section{Ethics approval}

This study did not involve purposeful killing of animals. Professional personnel collected blood and liver samples mostly from hunted-harvested wild boar during the hunting season. These animals were legally hunted under Spanish and EU legislation and all hunters had hunting licenses. No ethical approval was deemed necessary; all collection of samples was performed for routine procedures before the design of this study in compliance with the Ethical Principles in Animal Research. Thus, blood or liver samples were not collected specifically for this study. Protocols, amendments and other resources were all done according to the guidelines approved by each Autonomous government following the R.D.1201/2005 of the Ministry of Presidency of Spain.

\section{Consent for publication}

Not applicable.

\section{Competing interests}

We declare no competing interests. At no time have the authors or their institution received payment or services from a third party for any aspect of the submitted work (data monitoring board, study design, manuscript preparation, statistical analysis, and so on).

\section{Publisher's Note}

Springer Nature remains neutral with regard to jurisdictional claims in published maps and institutional affiliations.

\section{Author details}

${ }^{1}$ Infectious Diseases Unit. Instituto Maimonides de Investigación Biomédica de Córdoba (IMIBIC), Hospital Universitario Reina Sofía de Córdoba. Universidad de Córdoba, $2^{\circ}$ Floor. Box 134.Avenida Menendez Pidal s/n 14004 Córdoba, Spain. ${ }^{2}$ Animal Health Department. Veterinary Science College, Universidad de Córdoba, 14014 Cordoba, Spain. ${ }^{3}$ Animal Pathology Department. Veterinary Science College, Universidad de Córdoba, Cordoba, Spain. ${ }^{4}$ Unidad de Enfermedades Infecciosas. Hospital Provincial, Complejo Hospitalario reina Sofía de Córdoba, Avenida Menendez Pidal s/n, 14006 Cordoba, Spain.

Received: 21 November 2017 Accepted: 15 February 2018 Published online: 27 February 2018

\section{References}

1. Dalton HR, Bendall R, ljaz S, Banks M. Hepatitis E: an emerging infection in developed countries. Lancet Infect Dis. 2008;8:698-709.

2. Hartl J, Otto B, Madden RG, Webb G, Woolson KL, Kriston L, Vettorazzi E, Lohse AW, Dalton HR, Pischke S. Hepatitis E Seroprevalence in Europe: a meta-analysis. Viruses. 2016;8:E211.

3. Doceul V, Bagdassarian E, Demange A, Pavio N. Zoonotic hepatitis E virus: classification, animal reservoirs and transmission routes. Viruses. 2016;8:E270.

4. Lhomme S, Top S, Bertagnoli S, Dubois M, Guerin JL, Izopet J. Wildlife reservoir for hepatitis E virus, southwestern France. Emerg Infect Dis. 2015;21:1224-6.

5. Pavio N, Meng XJ, Doceul V. Zoonotic origin of hepatitis E. Curr Opin Virol. 2015;10:34-41.

6. Rivero-Juarez A, Frias M, Martinez-Peinado A, Risalde MA, Rodirguez-Cano D, Camacho A, García-Bocanegra I, Cuenca-Lopez F, Gomez-Villamandos JC, 
Rivero A. Familial hepatitis E outbreak linked to wild boar meat consumption. Zoonoses Public Health. 2017;64:561-5.

7. Schlosser J, Eiden M, Vina-Rodriguez A, Fast C, Dremek P, Lange E, Ulrich RG, Groschup MH. Natural and experimental hepatitis E virus genotype 3-infection in European wild boar is transmissible to domestic pigs. Vet Res. 2014;45:121.

8. Hoofnagle JH, Nelson KE, Purcell RH. Hepatitis E. N Engl J Med. 2012;367:1237-44.

9. Rivero-Juarez A, Martinez-Dueñas L, Martinez-Peinado A, Camacho A, Cifuentes C, Gordon A, Frias M, Torre-Cisneros J, Pineda JA, Rivero A. High hepatitis $E$ virus seroprevalence with absence of chronic infection in HIVinfected patients. J Inf Secur. 2015;70:624-30.

10. Weller $R$, Todt $D$, Engelmann $M$, Friesland $M$, Wedemeyer $H$, Pietschmann $T$, Steinmann E. Apolipoprotein E polymorphisms and their protective effect on hepatitis E virus replication. Hepatology. 2016;64:2274-6.

11. Mansuy JM, Gallian P, Dimeglio C, Saune K, Arnaud C, Pelletier B, Morel P, Legrand D, Tiberghien P, Izopet J. A nationwide survey of hepatitis E viral infection in French blood donors. Hepatology. 2016;63:1145-54

12. Hunter JG, Madden R, Stone A, Osborne N, Wheeler B, Vine L, Dickson A, Barlow M, Lewis J, Bendall RP. Coastal clustering of HEV; Cornwall, UK. Eur J Gastroenterol Hepatol. 2015;28:323-7.

13. Arenas-Montes A, García-Bocanegra I, Paniagua J, Franco JJ, Miró F, FernándezMorente M, Carbonero A, Arenas A. Blood sampling by puncture in the cavernous sinus from hunted wild boar. Eur J Wild Res. 2013;59:299-303.

14. Abravanel F, Sandres-Saune K, Lhomme S, Dubois M, Mansuy JM, Izopet J. Genotype 3 diversity and quantification of hepatitis E virus RNA. J Clin Microbiol. 2012;50:897-902.

15. Schielke A, Ibrahim V, Czogiel I, Faber M, Schrader C, Dremsek P, Ulrich RG, Johne R. Hepatitis E virus antibody prevalence in hunters from a district in Central Germany, 2013: a cross-sectional study providing evidence for the benefit of protective gloves during disembowelling of wild boars. BMC Infect Dis. 2015;15:440.

16. Kaci S, Nöckler K, Johne R. Detection of hepatitis E virus in archived German wild boar serum samples. Vet Microbiol. 2008;128:380-5.

17. Adlhoch C, Wolf A, Meisel H, Kaiser M, Ellerbrok H, Pauli G. High HEV presence in four different wild boar populations in east and West Germany. Vet Microbiol. 2009;139:270-8.

18. Mazzei M, Nardini R, Verin R, Forzan M, Poli A, Tolari F. Serologic and molecular survey for hepatitis E virus in wild boar (Sus Scrofa) in Central Italy. New Microbes New Infect. 2015;7:41-7.

19. Rutjes SA, Lodder-Verschoor F, Lodder WJ, van der Giessen J, Reesink H, Bouwknegt M, de Roda Husman AM. Seroprevalence and molecular detection of hepatitis $\mathrm{E}$ virus in wild boar and red deer in The Netherlands. J Virol Methods. 2010;168:197-206.

20. Ivanova A, Tefanova V, Reshetnjak I, Kuznetsova T, Geller J, Lundkvist Å, Janson M, Neare K, Velström K, Jokelainen P, Lassen B, Hütt P, Saar T, Viltrop A, Golovljova I. Hepatitis E virus in domestic pigs, wild boars, pig farm workers, and hunters in Estonia. Food Environ Virol. 2015;7:403-12.

21. Reuter G, Fodor D, Forgách P, Kátai A, Szucs G. Characterization and zoonotic potential of endemic hepatitis E virus (HEV) strains in humans and animals in Hungary. J Clin Virol. 2009:44:277-81.

22. de Deus N, Peralta B, Pina S, Allepuz A, Mateu E, Vidal D, Ruiz-Fons F, Martín M, Gortázar C, Segalés J. Epidemiological study of hepatitis E virus infection in European wild boars (Sus scrofa) in Spain. Vet Microbiol. 2008;129:163-70.

23. Burri C, Vial F, Ryser-Degiorgis MP, Schwermer H, Darling K, Reist M, Wu N, Beerli O, Schöning J, Cavassini M, Waldvogel A. Seroprevalence of hepatitis $E$ virus in domestic pigs and wild boars in Switzerland. Zoonoses Public Health. 2014;61:537-44.

24. Carpentier A, Chaussade H, Rigaud E, Rodriguez J, Berthault C, Boué F, Tognon M, Touzé A, Garcia-Bonnet N, Choutet P, Coursaget P. High hepatitis E virus seroprevalence in forestry workers and in wild boars in France. J Clin Microbiol. 2012;50:2888-93.

25. Jori F, Laval M, Maestrini O, Casabianca F, Charrier F, Pavio N. Assessment of domestic pigs, wild boars and feral hybrid pigs as reservoirs of hepatitis $E$ virus in Corsica, France. Viruses. 2016;8(8):236.

26. Schielke A, Sachs K, Lierz M, Appel B, Jansen A, Johne R. Detection of hepatitis $E$ virus in wild boars of rural and urban regions in Germany and whole genome characterization of an endemic strain. Virol J. 2009:6:58.

27. Weigand K, Weigand K, Schemmerer M, Müller M, Wenzel JJ. Hepatitis E Seroprevalence and genotyping in a cohort of wild boars in southern Germany and eastern Alsace. Food Environ Virol. 2017; https://doi.org/10. 1007/s12560-017 9329-x
28. Zhu FC, Huang SJ, Wu T, Zhang XF, Wang ZZ, Ai X, Yan Q, Yang CL, Cai JP, Jiang HM, Wang YJ, Ng MH, Zhang J, Xia NS. Epidemiology of zoonotic hepatitis E: a community-based surveillance study in a rural population in China. PLoS One. 2014;9:e87154.

29. Khuroo MS, Khuroo MS, Khuroo NS. Transmission of hepatitis E virus in developing countries. Viruses. 2016;8:E253.

30. Lu YH, Qian HZ, Hu AQ, Qin X, Jiang QW, Zheng YJ. Seasonal pattern of hepatitis $E$ virus prevalence in swine in two different geographical areas of China. Epidemiol Infect. 2013;141:2403-9.

31. Dalton HR, Stableforth W, Thurairajah $P$, Hazeldine $S$, Remnarace R, Usama W, Farrington L, Hamad N, Sieberhagen C, Ellis V, Mitchell J, Hussaini SH, Banks M, ljaz S, Bendall RP. Autochthonous hepatitis E in Southwest England: natural history, complications and seasonal variation, and hepatitis E virus IgG seroprevalence in blood donors, the elderly and patients with chronic liver disease. Eur J Gastroenterol Hepatol. 2008:20:784-90.

32. Mansuy JM, Abravanel F, Miedouge M, Mengelle C, Merviel C, Dubois M, Kamar N, Rostaing L, Alric L, Moreau J, Peron JM, Izopet J. Acute hepatitis E in south-west France over a 5-year period. J Clin Virol. 2009;44:74-7.

\section{Submit your next manuscript to BioMed Central and we will help you at every step:}

- We accept pre-submission inquiries

- Our selector tool helps you to find the most relevant journal

- We provide round the clock customer support

- Convenient online submission

- Thorough peer review

- Inclusion in PubMed and all major indexing services

- Maximum visibility for your research

Submit your manuscript at www.biomedcentral.com/submit
) Biomed Central 